\title{
Aqueous Extract of Solanum nigrum Leaves Induces Autophagy and Enhances Cytotoxicity of Cisplatin, Doxorubicin, Docetaxel, and 5-Fluorouracil in Human Colorectal Carcinoma Cells
}

\author{
Chen-Jei Tai, ${ }^{1,2}$ Chien-Kai Wang, ${ }^{1,2,3,4}$ Cheng-Jeng Tai, ${ }^{3,4}$ Yi-Feng Lin, ${ }^{5}$ Chi-Shian Lin, ${ }^{6}$ \\ Jiun-Yu Jian, ${ }^{2}$ Yu-Jia Chang, ${ }^{7,9,9}$ and Chun-Chao Chang, ${ }^{4,10}$ \\ ${ }^{1}$ Department of Chinese Medicine, Taipei Medical University Hospital, Taipei 11031, Taiwan \\ ${ }^{2}$ Department of Obstetrics and Gynecology, School of Medicine, College of Medicine, Taipei Medical University, Taipei 11031, Taiwan \\ ${ }^{3}$ Division of Hematology and Oncology, Department of Internal Medicine, Taipei Medical University Hospital, Taipei 11031, Taiwan \\ ${ }^{4}$ Department of Internal Medicine, School of Medicine, College of Medicine, Taipei Medical University, Taipei 11031, Taiwan \\ ${ }^{5}$ Division of General Surgery, Department of Surgery, Chi Mei Hospital Chiali, Tainan 72263, Taiwan \\ ${ }^{6}$ Graduate Institute of Medical Sciences, College of Medicine, Taipei Medical University, Taipei 11031, Taiwan \\ ${ }^{7}$ Graduate Institute of Clinical Medicine, College of Medicine, Taipei Medical University, Taipei 11031, Taiwan \\ ${ }^{8}$ Department of Surgery, Taipei Medical University and Hospital, Taipei 11031, Taiwan \\ ${ }^{9}$ Division of General Surgery, Department of Surgery, Taipei Medical University Hospital, Taipei Medical University, \\ Taipei 11031, Taiwan \\ ${ }^{10}$ Division of Gastroenterology and Hepatology, Department of Internal Medicine, Taipei Medical University Hospital, \\ Taipei 11031, Taiwan
}

Correspondence should be addressed to Chun-Chao Chang; chunchao@tmu.edu.tw

Received 14 March 2013; Revised 15 May 2013; Accepted 22 May 2013

Academic Editor: Jing Hua Wang

Copyright (C) 2013 Chen-Jei Tai et al. This is an open access article distributed under the Creative Commons Attribution License, which permits unrestricted use, distribution, and reproduction in any medium, provided the original work is properly cited.

Colorectal cancer is a common cancer worldwide, and chemotherapy is a mainstream approach for advanced and recurrent cases. Development of effective complementary drugs could help improve tumor suppression efficiency and control adverse effects from chemotherapy. The aqueous extract of Solanum nigrum leaves (AE-SN) is an essential component in many traditional Chinese medicine formulas for treating cancer, but there is a lack of evidence verifying its tumor suppression efficacy in colorectal cancer. The purpose of this study is to evaluate the tumor suppression efficacy of AE-SN using DLD-1 and HT-29 human colorectal carcinoma cells and examine the combined drug effect when combined with the chemotherapeutic drugs cisplatin, doxorubicin, docetaxel, and 5-fluorouracil. The results indicated that AE-SN induced autophagy via microtubule-associated protein 1 light chain $3 \mathrm{~A} / \mathrm{B}$ II accumulation but not caspase-3-dependent apoptosis in both cell lines. The $\mathrm{IC}_{50} \mathrm{~s}$ after 48 hours of treatment were 0.541 and $0.948 \mathrm{mg} / \mathrm{ml} \mathrm{AE-SN}$ in DLD-1 and HT-29, respectively. AE-SN also demonstrated a combined drug effect with all tested drugs by enhancing cytotoxicity in tumor cells. Our results suggest that AE-SN has potential in the development of complementary chemotherapy for colorectal cancer.

\section{Introduction}

Colorectal cancer is one of the most common types of cancer worldwide with particularly high incidences in developed countries [1]. In Taiwan, colorectal cancer is already the most common type of cancer and the third most common cause of cancer deaths [2]. Currently, surgery is still the only curative treatment for colorectal cancer. Although 75-80\% of newly diagnosed cases are localized or regional tumors, around $50 \%$ of patients suffer recurrence after surgery $[3,4]$. adjuvant therapy such as postoperative chemotherapy is used to eliminate remaining lesions and help control the risk of recurrence. Chemotherapy is also one of the main treatment approaches in advanced and recurrent cases. However, chemotherapy is often associated with adverse side effects in patients, particularly in the elderly population. Various drug 
resistance problems in colorectal cancer cases also reduce the response rates. These clinical features limit the performance of chemotherapy in patients. Hence, in order to reduce systematic side effects and improve the tumor suppression capability of chemotherapy, the use of complementary and alternative medicine has become increasingly popular during the last few decades, particularly in Western countries [5-7]. Any effective drug which promotes the tumor suppression efficacy of chemotherapeutic regimens or eases the associated adverse effects may serve as an appropriate candidate to establish an integrated chemotherapy and improve clinical outcomes in cancer patients.

One approach in developing integrated chemotherapy is to choose a drug which enhances tumor cell suppression efficiency by increasing cytotoxicity using a different cell death mechanism from other drugs used in the regimen. In general, the tumor suppression mechanisms of current chemotherapeutic drugs are mainly based on disruption of cell cycle processes, resulting in cell apoptosis. For example, well-studied chemotherapeutic drugs such as the alkylating agents, cisplatin, and carboplatin inhibit DNA synthesis in tumor cell growth by forming DNA adducts [8, 9], whereas plant alkaloids, such as the taxanes, block tumor cell mitosis by stabilizing tubulin $[10,11]$. Other common drugs such as doxorubicin function as topoisomerase II inhibitors and interfere with DNA/RNA synthesis in tumor cells [12, 13]. The currently recommended chemotherapeutic drug for colorectal cancer is 5-fluorouracil (5-Fu) [3, 14-16], which activates apoptosis by incorporation of DNA/RNA on cancer cells [17]. Treatments using these common chemotherapeutic drugs normally lead to cell cycle arrest and activate the apoptotic process in tumor cells. Combining standard chemotherapeutics with antitumor drugs to induce tumor cell death via other molecular pathways would not only improve tumor suppression efficiency but also reduce the doses of chemotherapeutic drugs, which could help control adverse effects and may slow the development of drug resistance.

Traditional Chinese medicine (TCM) is based on the use of natural products and well-established theoretical approaches. TCM provides many potential candidates as effective drugs for integrated cancer chemotherapy, such as TJ-41 (Bu-Zhong-Yi-Qi-Tang) and PHY906 (Huang-QinTang) [18-20]. In TCM practice, a therapeutic formula is normally prepared as an aqueous extract mixed with various medical herbs. One major herb in this formula is responsible for relieving the target symptom, whereas other medicinal herbs are added to enhance the therapeutic effects or reduce the side effects of the major herb. Solanum nigrum (SN) is frequently used as an elemental ingredient for clinical TCM cancer therapy [8]. Recently, many in vitro studies have demonstrated the antitumor effects of SN extracts on various cancer types, including leukemia and prostate, liver, breast, lung, stomach, colon, bladder, and endometrial cancers [8, 21-24]. In these studies, the SN-related antitumor effect was thought to occur via activation of apoptosis and autophagy in human cancer cells, particularly when using the aqueous extract of SN (AE-SN) [22, 25]. However, most studies on the treatment effect on colon cancer have mainly assessed the tumor suppression capability of pure compounds such as solamargines and degalactotigonin [21], rather than evaluating the antitumor efficiency and mechanism of AE-SN. The tumor suppression efficacy of AE-SN in colon cancer cells therefore remains unclear. We previously observed that AESN has a combined drug effect with the standard chemotherapeutic drug docetaxel in human endometrial cancer cells [24]. This observation suggests that AE-SN may also enhance cytotoxicity of chemotherapeutic drugs in human colorectal cancer cells.

The aim of the present study is to evaluate the tumor suppression efficacy of AE-SN alone and combined drug effects of AE-SN with the common chemotherapeutic drugs cisplatin, doxorubicin, and 5-Fu docetaxel on human colorectal cells. This information could be helpful in improving the tumor suppression efficiency of chemotherapy for colorectal cancer.

\section{Materials and Methods}

2.1. Plant Materials and Preparation of AE-SN. In TCM practice, the drug form of $\mathrm{SN}$ is generally prepared as the aqueous extract of $\mathrm{SN}$ leaves (AE-SN). The preparation of $\mathrm{AE}-\mathrm{SN}$ for the present study was therefore based on the TCM processing method. Briefly, $50 \mathrm{~g}$ of the dried leaf part of Solanum nigrum was immersed in $750 \mathrm{~mL}$ distilled water. This raw solution was gradually heated to $100^{\circ} \mathrm{C}$ within $50 \mathrm{~min}$ and maintained at $100^{\circ} \mathrm{C}$ for one hour. This AE-SN solution was further concentrated to $1 \mathrm{~g} / \mathrm{mL}$.

2.2. Cell Culture. The human colorectal carcinoma cell lines, HT-29 and DLD-1, were a gift from Dr Pei-Yi Tsai (Department of Animal Pharmacology, Development Center for Biotechnology, Taipei, Taiwan) and purchased from the Bioresource Collection and Research Center (Hsinchu, Taiwan), respectively. Both HT-29 and DLD-1 cells contain a p53 mutation. Cells were cultured in Dulbecco's modified Eagle's medium/nutrient mixture F-12 medium (Gibco, Grand Island, NY, USA) with $100 \mathrm{U} / \mathrm{mL}$ of penicillin and $100 \mu \mathrm{g} / \mathrm{mL}$ streptomycin (Invitrogen Life Technologies, Carlsbad, CA, USA) at $37^{\circ} \mathrm{C}$ in a $5 \% \mathrm{CO}_{2}$ humidified incubator.

2.3. Cytotoxicity Assay and Microscopic Observation. HT-29 cells or DLD-1 cells were seeded into 96-well microplates at a density of $5 \times 10^{3}$ cells per well overnight and then treated with $0,0.05,0.1,0.2,0.5,1,2$, and $5 \mathrm{mg} / \mathrm{mL}$ AE$\mathrm{SN}$ for 24 or $48 \mathrm{hr}$. In order to clarify the autophagic cell death on AE-SN treated cells, three autophagy inhibitors, 3methyladenine (3-MA), bafilomycin A, or pepstatin A/E64d (Sigma-Aldrich, St Louis, MO, USA), were treated with AESN on HT-29 and DLD-1 cells. The cytotoxicity of AE-SN on tumor cells was then determined by 3-(4,5-dimethylthiazol2-yl)-2, 5-diphenyltetrazolium bromide (MTT) assay. A trypan blue exclusion test was also performed to confirm the cell viability determined by MTT assay. HT-29 cells or DLD-1 cells were seeded into 24 -well plates at a density of $3 \times 10^{4}$ cells per well overnight and then treated with $0,0.2$, 
0.5, or $1 \mathrm{mg} / \mathrm{mL}$ AE-SN. After $48 \mathrm{hr}$ incubation, cells were harvested by trypsinization and centrifuged at $100 \times \mathrm{g}$ for 5 min to collect the cell pellet which was then resuspended in prewarmed phosphate-buffered saline with trypan blue (Sigma-Aldrich, St Louis, MO, USA) at a 1:1 ratio for $3 \mathrm{~min}$ at room temperature. The number of live cells without trypan blue staining was counted by two independent observers using a hemocytometer under a microscope. In the study of AE-SN combined with cisplatin, doxorubicin, and docetaxel, cells were treated with a series of cisplatin, doxorubicin, or docetaxel with $0,0.5$, or $1 \mathrm{mg} / \mathrm{mL} \mathrm{AE-SN}$ for $48 \mathrm{hr}$. Cisplatin, doxorubicin and 5-fluorouracil (5-Fu) were purchased from Sigma-Aldrich (St. Louis, MO, USA) and docetaxel (Tyxan) from TTY Biopharm (Taipei, Taiwan). Cell morphology was observed with a Nikon Eclipse TS100 optical microscope (Nikon Instruments, Melville, NY, USA) and photographed at 100x magnification. Cytotoxicity was also determined by MTT assay.

2.4. Western Blotting Analysis of Cell Death Markers. HT29 and DLD- 1 cells $\left(5 \times 10^{5}\right.$ cells per dish) were seeded in $6 \mathrm{~cm}$ dishes overnight and incubated with 0 or $1 \mathrm{mg} / \mathrm{mL}$ AE-SN alone, or in combination with cisplatin, doxorubicin, or docetaxel for $48 \mathrm{hr}$. Cells were harvested by RIPA buffer (150 mM NaCl, $50 \mathrm{mM}$ pH 7.5 Tris-HCL, 1\% NP-40, 0.5\% deoxycholate, $0.1 \%$ SDS, $1 \mathrm{mM}$ PMSF, $10 \mu \mathrm{g} / \mathrm{mL}$ leupeptin and $100 \mu \mathrm{g} / \mathrm{mL}$ aprotinin). The total protein concentration of the cell extracts was determined by a Bio-Rad protein assay kit (Bio-Rad Laboratories, Hercules, CA, USA). Each cell extract was then equalized to $30 \mu \mathrm{g}$ and separated using $12 \%$ sodium dodecyl sulfate polyacrylamide gel electrophoresis. The proteins were transferred onto a polyvinylidene fluoride membrane (Pall Corp, Port Washington, NY, USA) and probed with the primary antibodies, caspase3 (1:1,000), mammalian microtubule-associated protein 1 light chain 3 A/B (LC3A/B, 1:1,000), and glyceraldehyde 3-phosphate dehydrogenase (GAPDH, 1:10,000), followed by donkey anti-rabbit horseradish peroxidase-conjugated secondary antibody $(1: 10,000$, Santa Cruz Biotechnology, Santa Cruz, CA, USA). This anti-LC3 A/B identifies the LC3 A/B I and II forms with molecular masses of 16 and $14 \mathrm{kDa}$, respectively. The accumulation of LC3 A/B II forms is considered a protein marker for activation of autophagy [26], whereas the anticaspase- 3 recognizes procasapse- 33 with a mass of $35 \mathrm{kDa}$ and cleaved caspase- 3 with masses of 19 and $17 \mathrm{kDa}$. Anti-caspase-3 and LC3 A/B were purchased from Cell Signaling Technology (Danvers, MA, USA), and antiGAPDH was purchased from Abfroniter (Seoul, Republic of Korea). Immunoreactivity was then detected with a WesternBright electrochemiluminescence Western blotting detection kit (Advabsta, Menlo Park, CA, USA). Semiquantitative analysis of the intensity of the immunoreactive bands was performed by ImageJ software (National Institutes of Health, Bethesda, MD, USA).

2.5. Statistical Analysis. Data from cell viability and semiquantitative Western blotting analysis were presented as mean \pm stand and derivation (SD). Statistical significance was analyzed by Student's $t$-test when comparing two different groups and one-way ANOVA when examining the dose-dependent effect. Statistical analysis was performed by SPSS (SPSS Inc, Chicago, IL, USA).

CalcuSyn software (Biosoft, Cambridge, UK) was used for the statistical analysis of the half maximal inhibitory concentration $\left(\mathrm{IC}_{50}\right)$ of AE-SN determined by MTT assay and for the combined effects of AE-SN with chemotherapeutic drugs. Statistical analysis of the combined drug effects with the CalcuSyn software is based on the median-effect method and evaluated by the combination index (CI) value; a synergistic effect of two drugs was determined when the calculated CI value was less than 1 [27].

\section{Results}

3.1. AE-SN Cytoxicity and Induction of Autophagy in HT-29 and DLD-1 Human Colorectal Carcinoma Cells. As shown in Figure 1, AE-SN induced cytotoxicity in both DLD-1 and HT-29 cells in a dose-dependent manner. According to the cytotoxicity results obtained from MTT assay, the $\mathrm{IC}_{50} \mathrm{~s}$ after $48 \mathrm{hr}$ AE-SN treatment were 0.541 and $0.948 \mathrm{mg} / \mathrm{mL}$ AE-SN in DLD-1 and HT-29 cells, respectively (Table 1). In contrast, the trypan blue exclusive test indicated that the cell viability of DLD-1 under $0.5 \mathrm{mg} / \mathrm{mL}$ AE-SN treatment was $50.1 \%$, whereas that of HT-29 under $1.0 \mathrm{mg} / \mathrm{mL}$ AE-SN treatment was $37.4 \%$. These conflicting results indicated that the MTT assay may underestimate the real cytotoxicity of AE-SN because of disruption of mitochondrial metabolism. Under microscopic inspection, lipid-like droplets were observed in AE-SN-treated DLD-1 and HT-29 cells (Figures 2(a)$2(d))$. This morphological feature suggested that AE-SNtreated cells were in the autophagic process which may be related to AE-SN-induced cytotoxicity. On the other hand, no apoptosis-related morphological changes such as cell shrinkage or chromatin condensation were observed in AE$\mathrm{SN}$-treated colorectal carcinoma cells. To further examine the cell death mechanisms involved in AE-SN-induced cytotoxicity, the activation of caspase-3, the protein marker for apoptosis, and the accumulation of LC3 A/B II, the protein marker for autophagy, were determined by western blotting analysis. Figures 2(e) and 2(f) demonstrate that accumulation of LC3 A/B II was significantly increased in AE-SN-treated colorectal carcinoma cells, whereas activation of caspase3 was not observed. The accumulation of LC3 A/B II is a protein marker which identifies autophagy in cells, and Western blotting analysis indicated that AE-SN treatment increased LC3 A/B II accumulation 12.83- and 7.08- fold in DLD-1 and HT-29 cells, respectively (Figure 2(e)). These results suggested that $\mathrm{AE}-\mathrm{SN}$ was effective in suppressing tumor cell growth in DLD-1 and HT-29 human colorectal carcinoma cells and induced accumulation of LC3 A/B II and the autophagic process, but not caspase-3-dependent apoptosis.

To clarify the role of AE-SN-activated autophagy on HT-29 and DLD-1 cells, AE-SN-treated HT-29 and DLD-1 cells were also cotreated with autophagic inhibitors: 3-MA, bafilomycin A, or pepstatin A/E64d. 3-MA is a class III 
TABLE 1: $\mathrm{IC}_{50}$ of AE-SN alone and in combination with cisplatin, doxorubicin, docetaxel, or 5-Fu in DLD-1 and HT-29 cells.

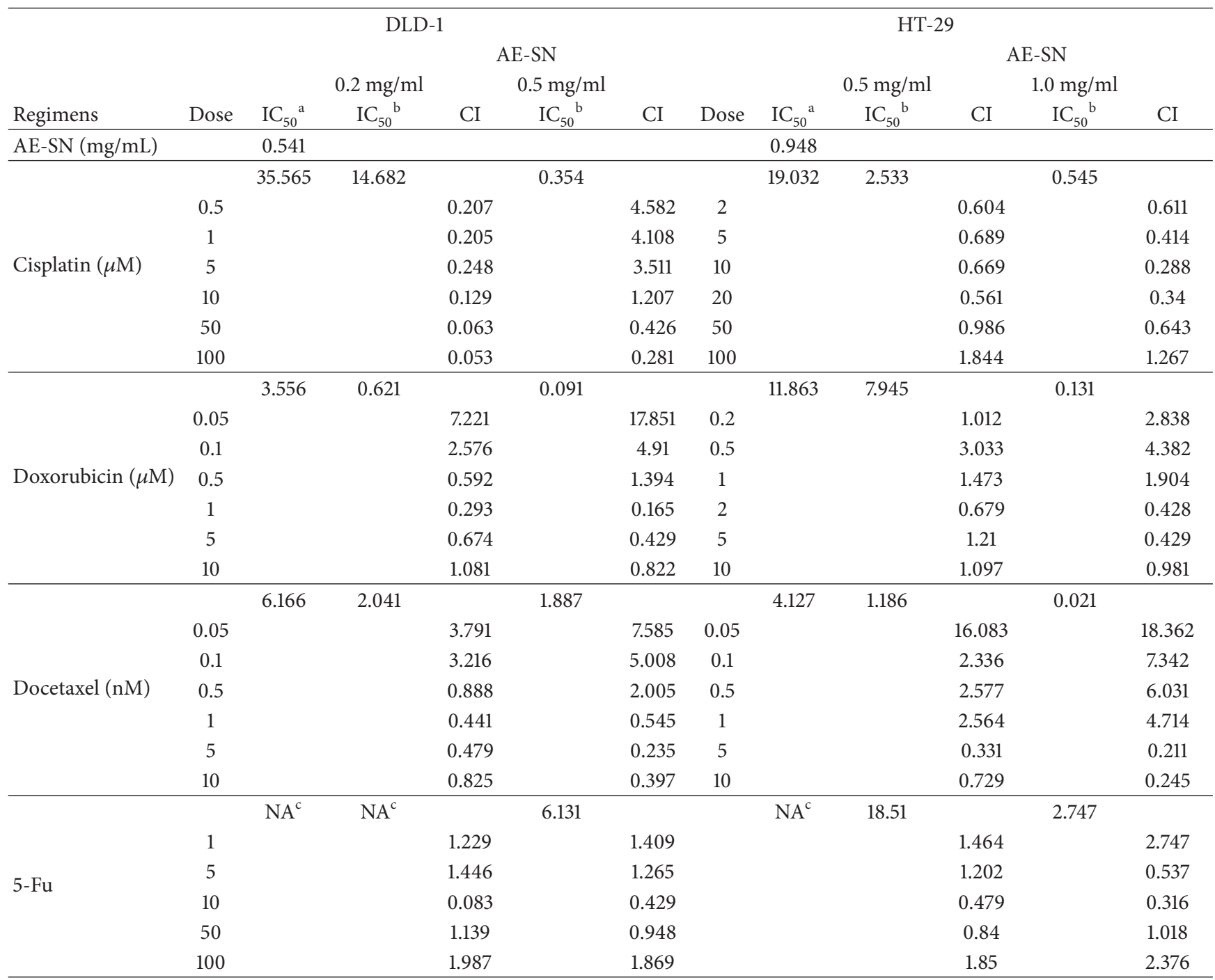

${ }^{a}$ Cells treated by AE-SN alone; ${ }^{b}$ cells treated by a combination of AE-SN and the respective chemotherapeutic drug.

AE-SN: aqueous extract of Solanum nigrum; $\mathrm{IC}_{50}$ : half maximal inhibitory concentration.

$\mathrm{CI}<1$ = synergistic effect.

${ }^{\mathrm{c}} \mathrm{NA}$ : data not available.

phosphoinositide-3 kinase inhibitor to block LC3 A/B I to II conversion [28], bafilomycin A is a lysosomal inhibitor to prevent the fusion of lysosomes and autophagosomes [29], and pepstatin $\mathrm{A} / \mathrm{E} 64 \mathrm{~d}$ is a cathepsins inhibitor to interfere with autolysosomal digestion [30]. As shown in Figures 3(a), slightly recovery of cell viability was observed on AE-SN and autophagic inhibitors cotreated HT-29 cells, whereas no difference was observed in DLD-1 cells. Cotreatment of AESN and 3-MA only reduced AE-SN-induced accumulation of LC-3 A/B II from 3.33- to 2.5-fold of control in HT-29 cells (Figure 3(b)). These results suggested that autophagy was partly involved in AE-SN-induced cell death in HT-29, but not DLD-1 cells.

3.2. Combined Drug Effects of AE-SN and Cisplatin, Doxorubicin, Docetaxel, and 5-Fu. Since AE-SN effectively induced caspase-3- independent cell death in DLD-1 and HT-29 cells, the present study further examined the potential of AE-SN in combination with chemotherapeutic drugs which are associated with apoptotic cell death. Tumor cells were treated by serial doses of four chemotherapeutic drugs, cisplatin, doxorubicin, docetaxel or 5-fu alone or in combination with AE-SN for $48 \mathrm{hr}$. According to previous results, HT-29 cells are less sensitive to AE-SN and therefore the selected AE-SN doses for combination treatment were 0.5 and $1.0 \mathrm{mg} / \mathrm{mL}$, whereas doses of 0.2 and $0.5 \mathrm{mg} / \mathrm{mL}$ were chosen for DLD-1 cells. Cytotoxicity was determined by MTT assay and the combined drug effect was further analyzed. AE-SN presented an enhanced cytotoxicity in combination with all four chemotherapeutic drugs in both cell lines (Figure 4). Analysis showed the synergy of AE-SN combined with each chemotherapeutic drug (CI less than 1) (Table 1). The $\mathrm{IC}_{50}$ of each regimen also significantly decreased in 


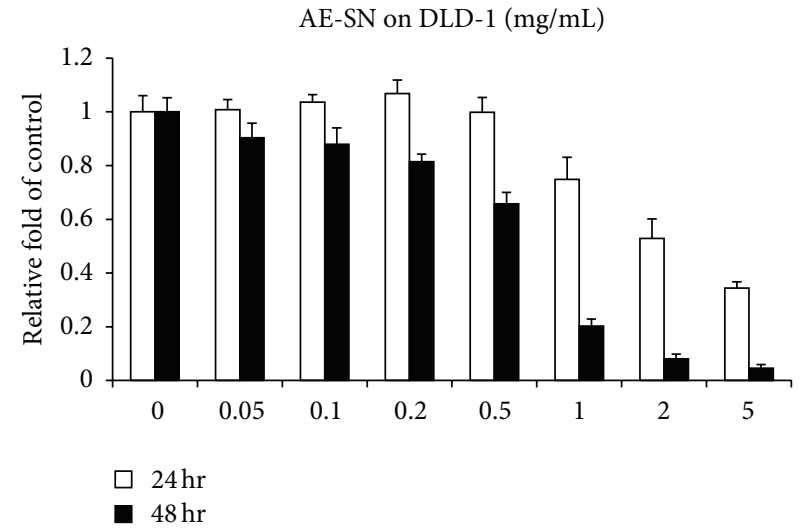

(a)

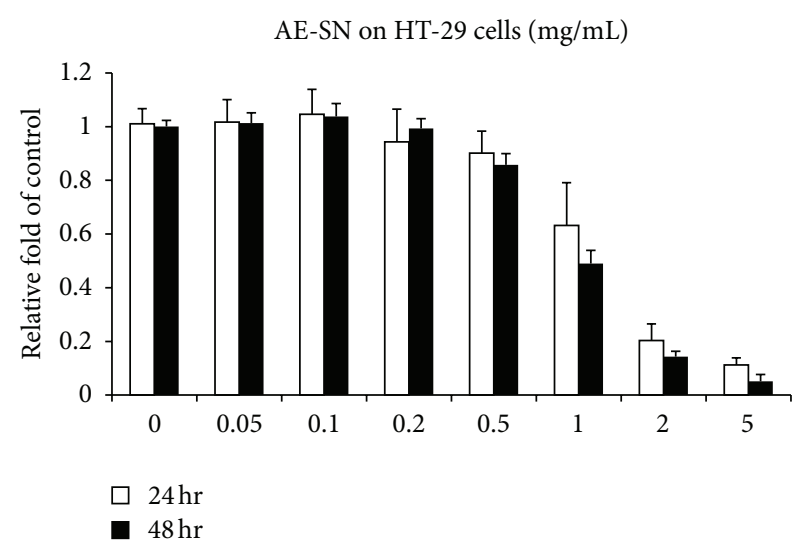

(b)

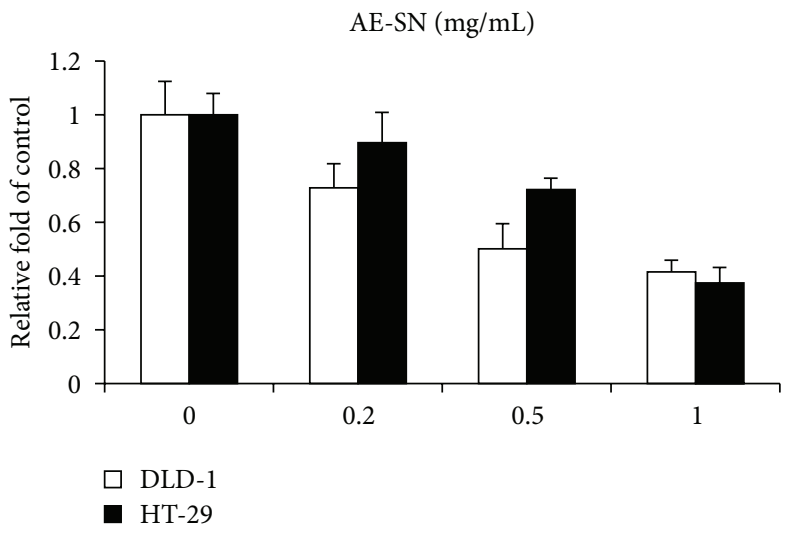

(c)

FIgURE 1: Cytotoxicity of AE-SN in DLD-1 and HT-29 human colorectal carcinoma cells (a); DLD-1 cells were treated with 0.05 to $5 \mathrm{mg} / \mathrm{mL}$ AE-SN for 24 or $48 \mathrm{hr}$; (b), HT-29 cells were treated with 0.05 to $5 \mathrm{mg} / \mathrm{mL}$ AE-SN for $24 \mathrm{hr}$; the cytotoxicity of (a) and (b) was analyzed by MTT assay; (c)DLD-1 or HT-29 cells were treated with 0.2 to $1 \mathrm{mg} / \mathrm{mL}$ AE-SN; and the cytotoxicity was analyzed by a trypan blue exclusion test. Experiments were performed in triplicate and data are shown as mean \pm SD. Both cell lines showed dose-dependent effects with AE-SN treatment at 24 and $48 \mathrm{hr}$ in the MTT assay and trypan blue exclusion test (one-way ANOVA, $P<0.001$ ). AE-SN: aqueous extract of Solanum nigrum: MTT: 3-(4,5-dimethylthiazol-2-yl)-2,5-diphenyltetrazolium bromide.

AE-SN-combined treatment in comparison with each chemotherapeutic drug alone (Table 1). Together, these in vitro results suggest that AE-SN can potentially enhance the tumor suppression effect in human colorectal carcinoma cells when combined with cisplatin, doxorubicin, docetaxel and, 5-Fu.

\subsection{Activation of LC3 $A / B$ and Caspase-3 in AE-SN and} Chemotherapeutic Drug-Treated Cancer Cells. The four tested chemotherapeutic drugs are well known to induce apoptosis via activation of caspase-3 in many tumor cells. This raised a possibility that AE-SN-enhanced cytotoxicity is due to a combined effect of AE-SN-induced caspase-3- independent cell death and chemotherapeutic drug-induced apoptotic cell death. In order to examine this hypothesis, DLD-1 cells or HT-29 cells were treated with 0 or $1 \mathrm{mg} / \mathrm{mL}$ AE-SN in combination with cisplatin $(50$ or $20 \mu \mathrm{M})$, doxorubicin $(5 \mu \mathrm{M}$ for both), docetaxel (1 nM for both), and 5-Fu (50 $\mu \mathrm{M})$ for $48 \mathrm{hr}$ and total protein extracts were harvested. The apoptotic protein marker, cleaved caspase-3, and autophagic protein marker, LC3 A/B II, were then determined in the total protein extracts of the cells. As shown in Figure 5(a), all tested drugs activated caspase- 3 and produced cleaved caspase-3 in DLD-1, but not HT-29 cells, whereas AE-SN increased LC3 A/B II in both cell lines. Semiquantitative data further confirmed that AE-SN treatment induced LC3 A/B II accumulation in chemotherapeutic drug-treated cells (Figure 5(b)). In cisplatin-treated cells, cotreatment with $1 \mathrm{mg} / \mathrm{mL}$ AE-SN increased LC3 A/B II 3.35- and 4.78-fold, whereas in docetaxel treatment, AE-SN also increased the autophagic marker by 3.36- and 3.15-fold in DLD-1 and HT-29 cells, respectively. In combination with 5-Fu, AE-SN induced 3.03- and 2.65-fold of LC3 A/B II accumulation, similar to docetaxel. In doxorubicin-treated DLD-1 and HT29 cells, the fold induction of LC3 A/B II was 2.09- and 2.05fold, respectively. It is slightly lower than cisplatin, docetaxel, and 5-Fu. When both cell lines were exposed to a combination of AE-SN and the test drugs, activation of caspase3 and LC3 A/B II were observed together (Figure 5(a)). 


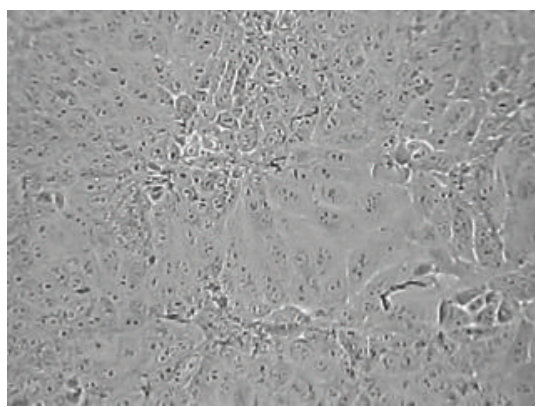

(a)

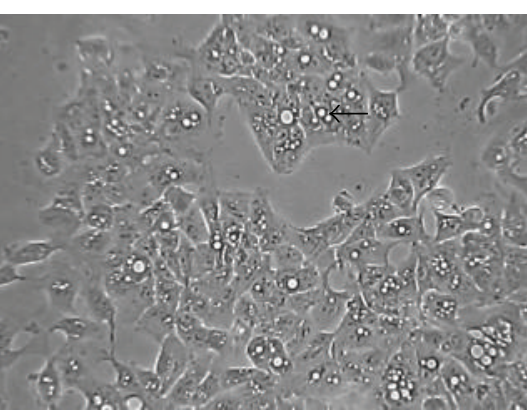

(b)

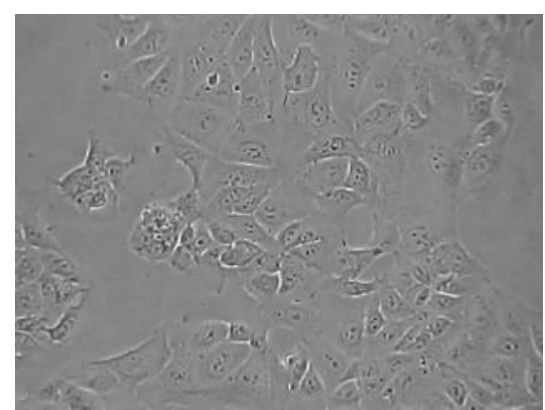

(c)

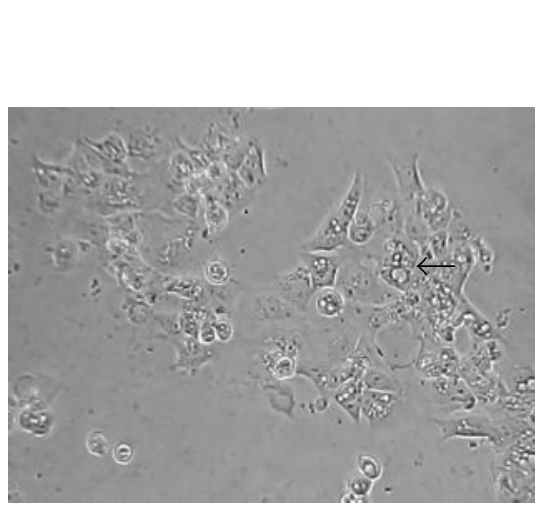

(d)

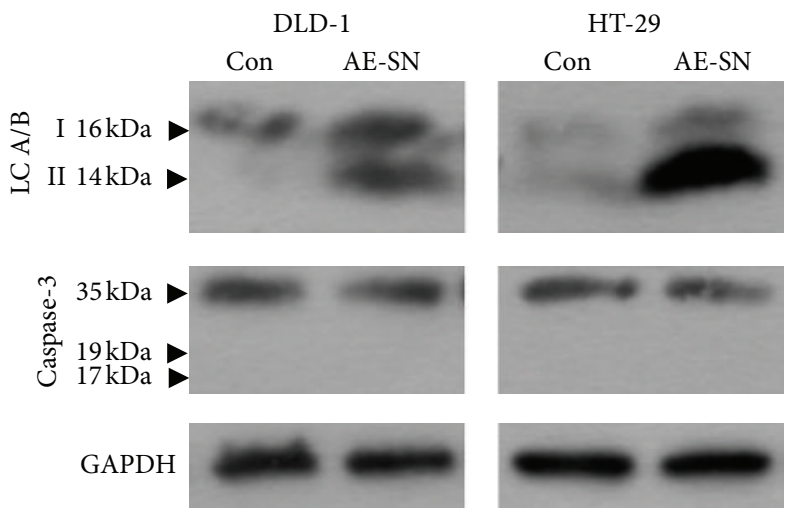

(e)

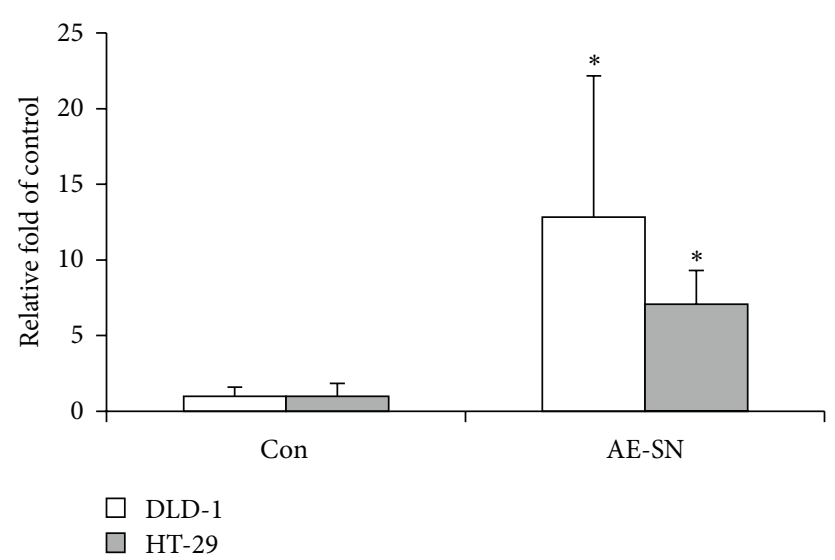

(f)

FIGURE 2: AE-SN induced morphological changes and LC-3 activation in DLD-1 and HT-29 cells. (a) and (b), DLD-1 cells were treated with 0 or $1 \mathrm{mg} / \mathrm{mL} \mathrm{AE-SN}$ for $48 \mathrm{hr}$, respectively; (c) and (d), HT-29 cells were treated with $0 \mathrm{or} 1 \mathrm{mg} / \mathrm{mL}$ AE-SN for $48 \mathrm{hr}$. Arrows indicate lipid droplet-like morphological changes in AE-SN-treated cells. Magnification $=100 \mathrm{x}$. (e) Total protein extracts were harvested from DLD-1 cells or HT-29 cells which were treated with 0 or $1 \mathrm{mg} / \mathrm{mL}$ AE-SN (control versus AE-SN) for $48 \mathrm{hr}$. Activation of caspase-3 and LC3 A/B in AE-SN-treated cells was determined by western blotting analysis. (f) Semiquantification of LC-3 A/B II in AE-SN-treated cells. Data presented are mean $\pm \mathrm{SD}(n=5)$. indicates statistical significance compared with $0 \mathrm{mg} / \mathrm{mL} \mathrm{AE}$-SN treatment using Student's $t$-test $(P<0.05)$. AE-SN: aqueous extract of Solanum nigrum; Con: control; GADPH: glyceraldehyde 3-phosphate dehydrogenase; LC-3 A/B II: mammalian microtubule-associated protein 1 light chain 3 A/B II.

This result suggested that the AE-SN enhanced cytotoxicity with chemotherapeutic drugs and also induced LC3 A/B II accumulation in colorectal carcinoma cells.

\section{Discussion}

The tumor suppression efficacy and related mechanisms of AE-SN have been examined in some cancer types. For instance, AE-SN induced both cleavage of caspase-3 and accumulation of LC3 A/B II in HepG2 human hepatocellular carcinoma cells [25], and similar results were observed in AU565 human breast carcinoma cells [22]. Interestingly, AESN treatment only induced LC3 A/B II accumulation but not cleavage of caspase-3in HEC-1A, HEC-1B, and KLE human endometrial cells [24], with similar results demonstrated in DLD-1 and HT-29, human colorectal carcinoma cells. 

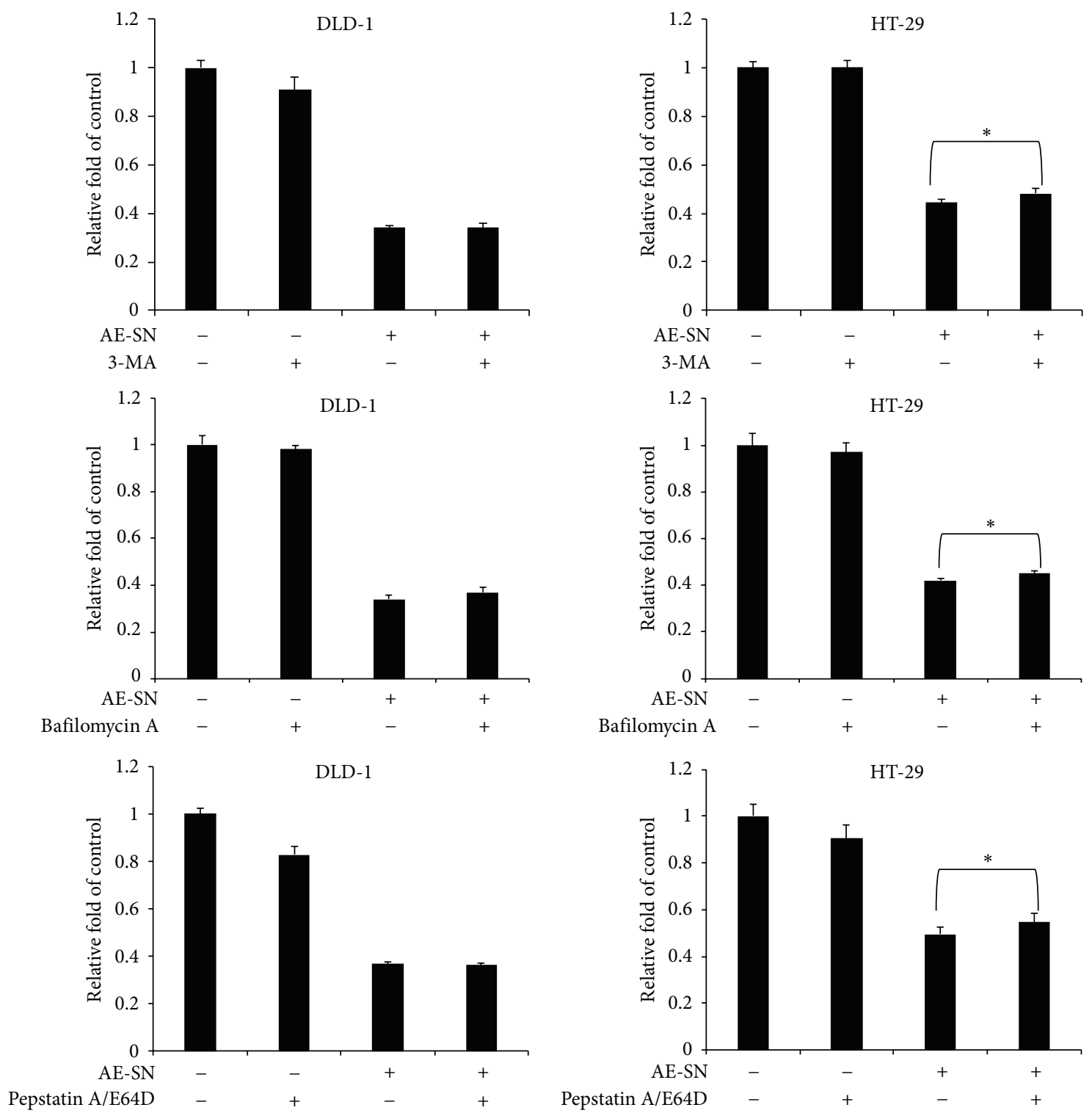

(a)

DLD-1

HT-29

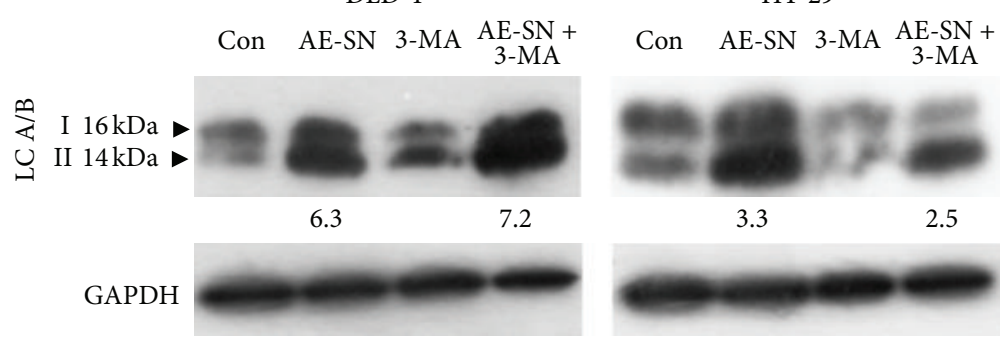

(b)

FIGURE 3: Inhibition of AE-SN induced autophagy by using 3-MA, bafilomycin (a), and pepstatin A/E64d on DLD-1 and HT-29 cells. (a) DLD-1 and HT-29 cells were treated with 0.5 or $1.0 \mathrm{mg} / \mathrm{mL}$ AE-SN, respectively, in combination with $1 \mu \mathrm{M} 3-\mathrm{MA}, 2 \mathrm{nM}$ bafilomycin A, or $2 \mu \mathrm{g} / \mathrm{mL}$ pepstatin A/E64d for $48 \mathrm{hr}$. Cytotoxicity was analyzed by MTT assay. Experiments were performed in triplicate and the data shown are mean $\pm \mathrm{SD}$. ${ }^{*}$ indicates statistical significance compared with $0 \mathrm{mg} / \mathrm{mL}$ AE-SN treatment using Student's $t$-test $(P<0.05)$. (b) DLD-1 and HT-29 cells were treated with control, AE-SN (1 mg/mL), 3-MA, or AE-SN plus 3-MA $(\mu \mathrm{M})$ for $48 \mathrm{hr}$ and accumtrluation of LC3 A/B II was determined by Western blotting. Numbers indicated fold induction of LC3 A/B II compared with control. AE-SN: aqueous extract of Solanum nigrum; MTT: 3-(4,5-dimethylthiazol-2-yl)-2, 5-diphenyltetrazolium bromide. 


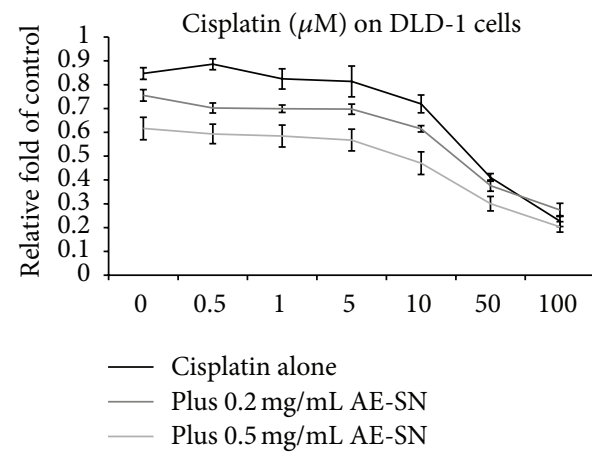

(a)

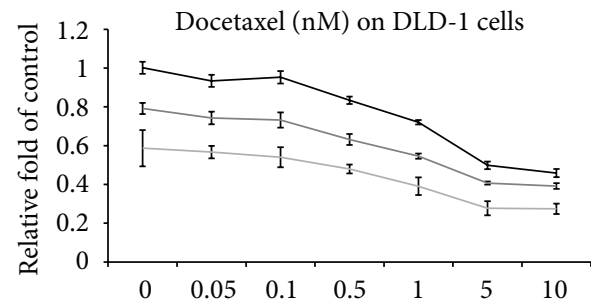

- Docetaxel (nM) on DLD-1 cells

— Plus $0.2 \mathrm{mg} / \mathrm{mL}$ AE-SN

_ Plus $0.5 \mathrm{mg} / \mathrm{mL}$ AE-SN

(c)

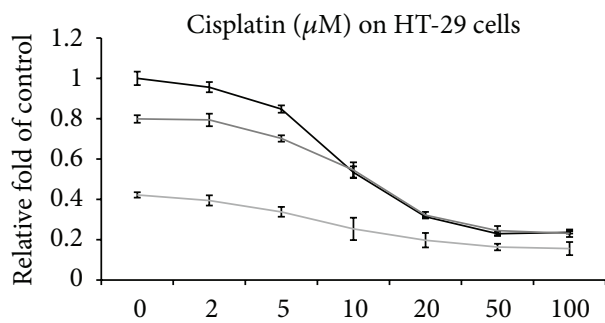

- Cisplatin alone

— Plus $0.5 \mathrm{mg} / \mathrm{mL}$ AE-SN

— Plus $1 \mathrm{mg} / \mathrm{mL}$ AE-SN

(e)

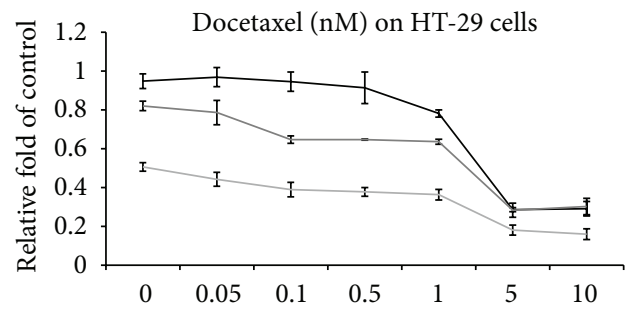

$\begin{array}{ll}\text { —_ } & \text { Docetaxel alone } \\ \text { Plus } 0.5 \mathrm{mg} / \mathrm{mL} \text { AE-SN } \\ \text { P Plus } 1 \mathrm{mg} / \mathrm{mL} \text { AE-SN }\end{array}$

(g)

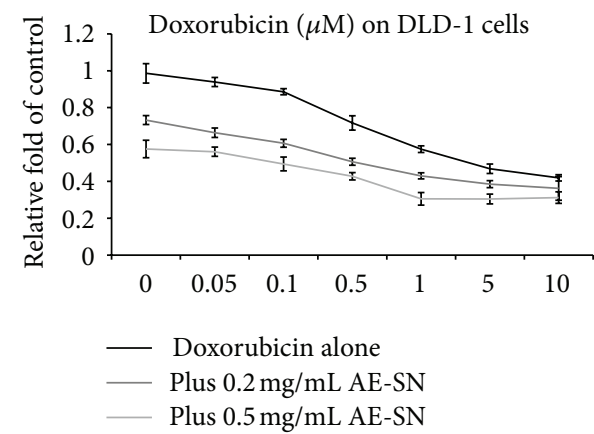

(b)

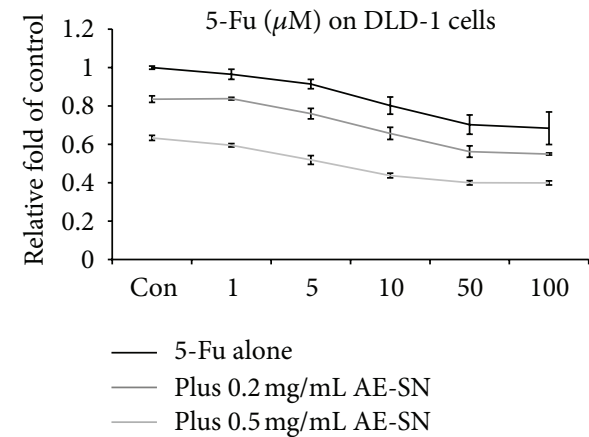

(d)

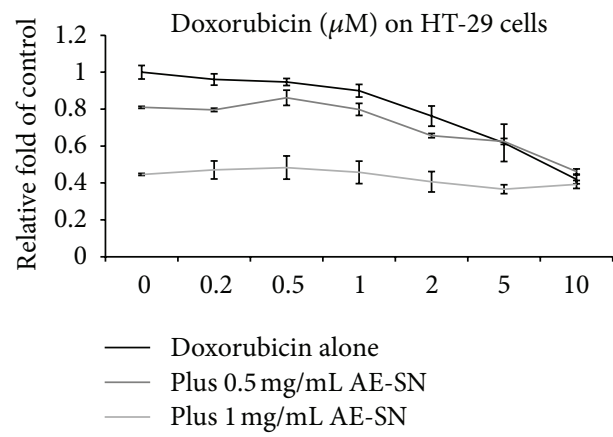

(f)

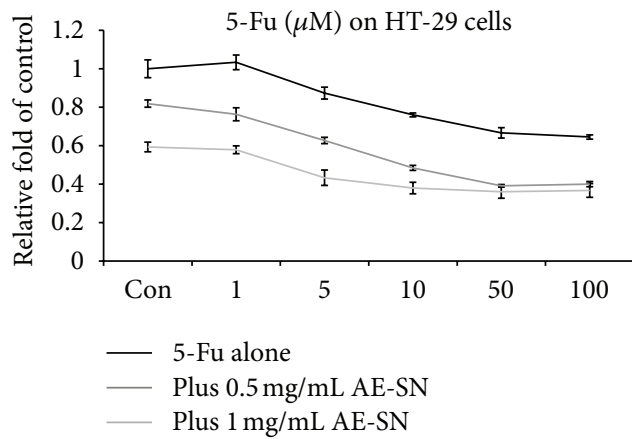

(h)

FIGURE 4: Cytotoxicity of a combination of AE-SN and the chemotherapeutic drugs, cisplatin, doxorubicin, docetaxel, or 5-Fu. (a), (b), (c), and (d), DLD-1 cells were treated with 0 to $100 \mu \mathrm{M}$ cisplatin, 0 to $10 \mu \mathrm{M}$ doxorubicin, 0 to $10 \mathrm{nM}$ docetaxel, 0 to $100 \mu \mathrm{M} 5$-Fu in combination with $0,0.2$ or $5 \mathrm{mg} / \mathrm{mL}$ AE-SN for $48 \mathrm{hr}$; (e), (f), (g), and (h) HT-29 cells were treated with 0 to $100 \mu \mathrm{M}$ cisplatin, 0 to $10 \mu \mathrm{M}$ doxorubicin, and 0 to $10 \mathrm{nM}$ docetaxel, or 0 to $100 \mu \mathrm{M}$ 5-Fu in combination with $0,0.5$ or $1 \mathrm{mg} / \mathrm{mL}$ AE-SN for 48 hr. Cytotoxicity was analyzed by MTT assay. Experiments were performed in triplicate and the data shown are mean \pm SD. AE-SN: aqueous extract of Solanum nigrum; MTT: 3-(4,5-dimethylthiazol-2-yl)-2, 5-diphenyltetrazolium bromide. 
DLD-1

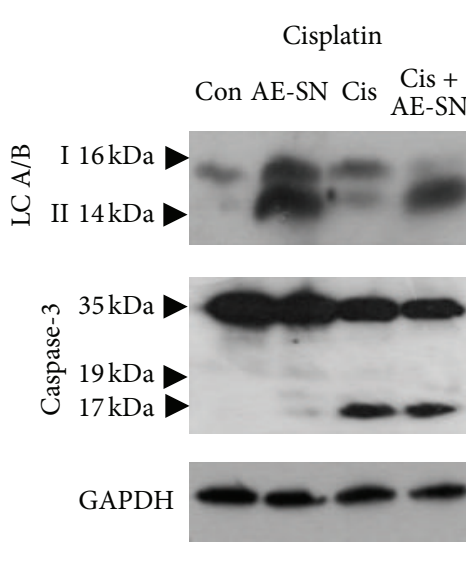

Cisplatin

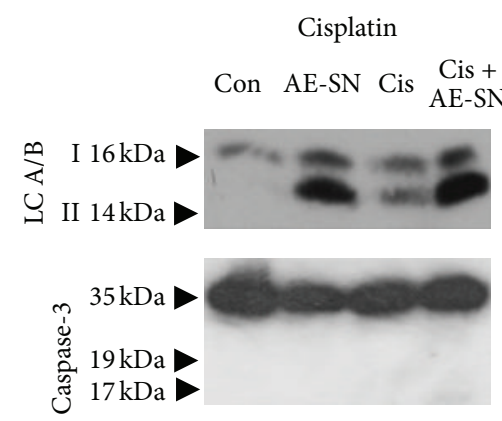

GAPDH

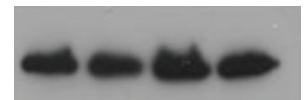

Doxorubicin Con AE-SN Dx $\begin{gathered}\text { Dx }+ \\ \text { AE-SN }\end{gathered}$
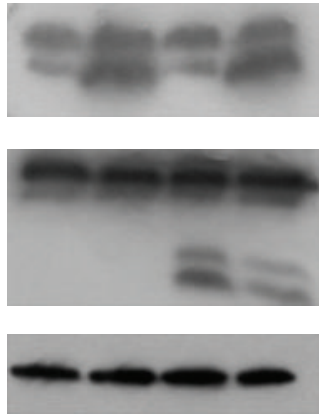

HT-29

Doxorubicin
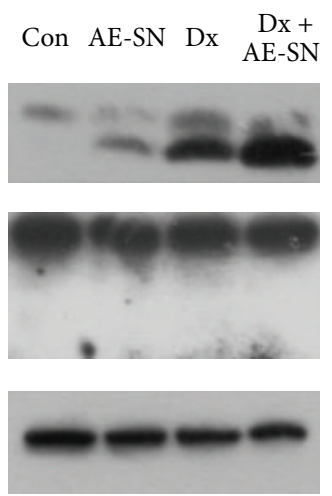

(a)

Docetaxel Con AE-SN Dc $\begin{gathered}\text { Dc }+ \\ \text { AE-SN }\end{gathered}$
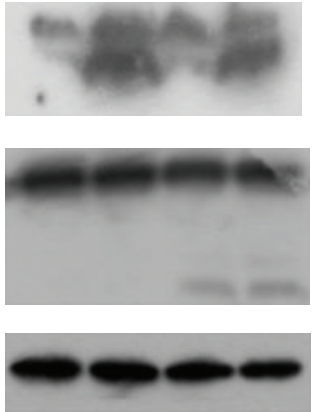

Docetaxel

Con AE-SN Dc Dc +
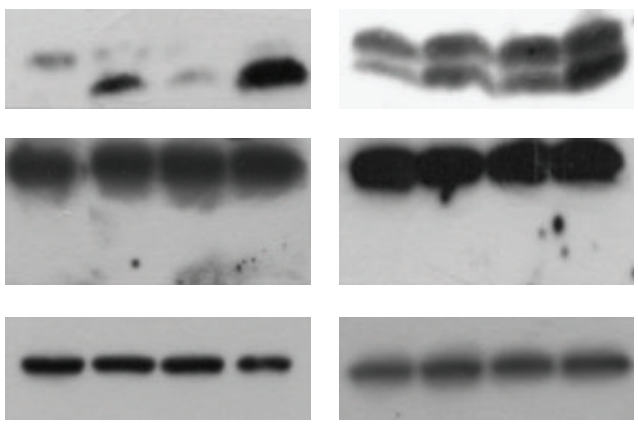

5-Fu
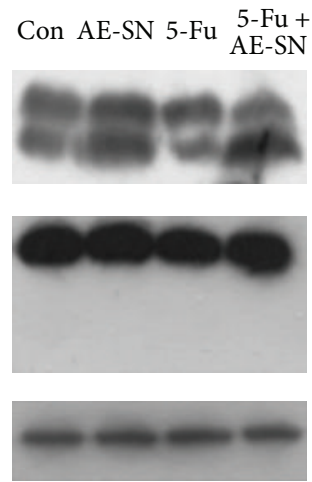

5-Fu

Con AE-SN 5-Fu $\begin{gathered}\text { 5-Fu }+ \\ \mathrm{AE}-\mathrm{SN}\end{gathered}$
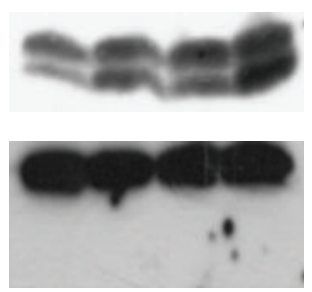

Induction fold of LC3 A/B II accumulation

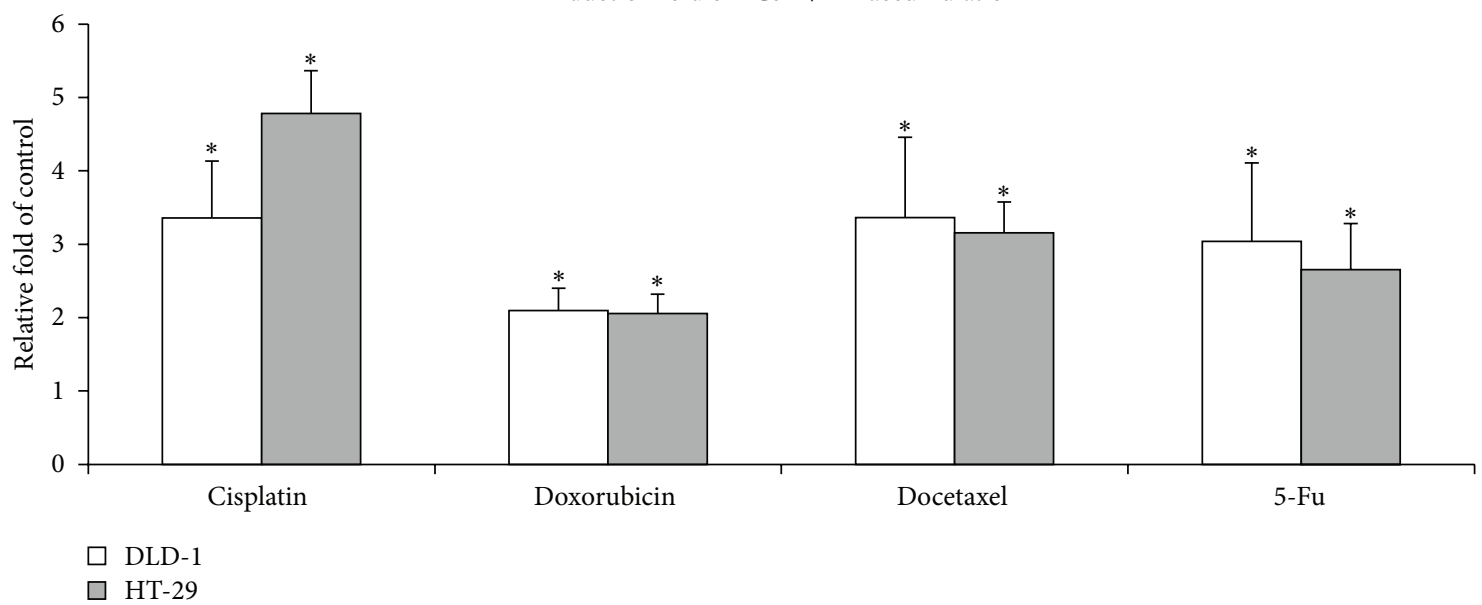

(b)

FIgURE 5: Activation of cell death markers, LC3 A/B and caspase-3 in DLD-1 and HT-29 cells treated with AE-SN and cisplatin, doxorubicin, or docetaxel. Both DLD-1 and HT-29 cells were treated with $0,1 \mathrm{mg} / \mathrm{mL}$ AE-SN, chemotherapeutic drugs alone, and a combination of $1 \mathrm{mg} / \mathrm{mL}$ AE-SN with chemotherapeutic drugs. The doses of cisplatin used were $50 \mu \mathrm{M}$ in DLD-1 and $20 \mu \mathrm{M}$ in HT-29. The dose of doxorubicin used was $5 \mu \mathrm{M}$ in DLD-1 and HT-29. The dose of docetaxel used was $1 \mathrm{nM}$ in DLD-1 and HT-29, whereas the dose of 5-Fu was $20 \mu \mathrm{M}$. After $48 \mathrm{hr}$ incubation, total protein extracts were harvested from cells. (a) Activation of LC3 A/B and caspase-3 in DLD-1 and HT-29 cells was determined by western blotting analysis; (b) semiquantification of LC3 A/B II is presented as the relative fold induction of the control as mean $\pm \mathrm{SD}(n=3) .{ }^{*}$ indicates statistical significance compared with $0 \mathrm{mg} / \mathrm{mL}$ AE-SN treatment using Student's $t$-test $(P<0.05)$. AE-SN: aqueous extract of Solanum nigrum; GADPH: glyceraldehyde 3-phosphate dehydrogenase; LC-3 A/B II: mammalian microtubule-associated protein 1 light chain 3 A/B II. 


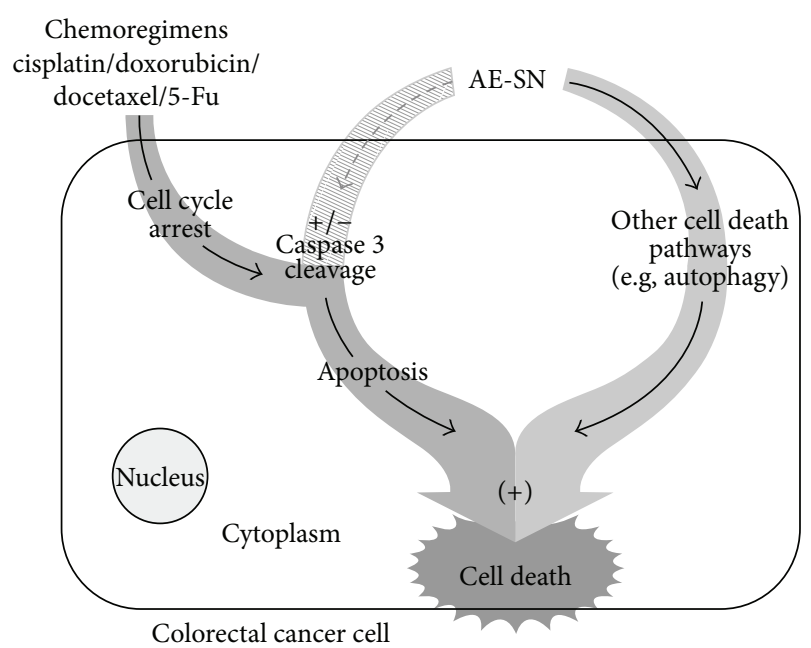

FIgURE 6: Proposed mechanism for the programmed cell death activated by AE-SN and chemotherapeutic drugs in human colorectal carcinoma cells. AE-SN-activated cell death can increase with cisplatin/doxorubicin/docetaxel/5-Fu-activated caspase-3-dependent or independent cell death $(+/-$ caspase- 3 cleavage) and result in further enhanced tumor cell death. $(+)$ indicates synergistic effect of AE-SN with chemotherapeutic drugs. Solid line: activated pathway; the dotted line: inactive pathway. AE-SN: aqueous extract of Solanum nigrum.

AE-SN-induced autophagy was suggested to cause cancer cell death, particularly in human hepatocellular carcinoma cells, HepG2 [25], and breast adenocarcinoma cells, AU565 [22]. However, autophagic cell death was only identified in HepG2 cells by using 3-MA, a phosphoinositide 3-kinase inhibitor [25]. In cancer cells, autophagy plays a dual role in performing cytoprotection or programmed cell death (reviewed by [31, 32]. For example, autophagy protected colorectal cancer cells HCT-116 and DLD-1 from 5-Fu-induced apoptosis [33]. In present study, autophagic inhibitors such as 3-MA, bafilomycin, and pepstatin A/E64d only slightly recovered cell viability and reduced accumulation of LC3 A/B II on HT-29 cells. These results indicated that AESN activated autophagy may partly contribute to AE-SNinduced cell death on HT-29 cells, but not DLD-1 cells. On the other hand, treatment of autophagic inhibitors cannot further promote cell death suggesting that AE-SN-induced autophagy may not be involved in cytoprotective effect on HT-29 and DLD-1 cells. Since both caspase-3- dependent apoptosis and autophagy were not fully responsible for AESN-induced cell death on HT-29 and DLD-1 cells, the exact cell death mechanism activated by AE-SN still remained unclear.

In the present study, AE-SN demonstrated an effective cytotoxicity in human colorectal carcinoma cells. Both DLD1 and HT-29 cell lines have p53 mutations and are partially resistant to the p53-mediated apoptotic pathway [34, 35]. AESN may therefore fail to activate apoptosis via p53 but may still be capable of activating cell death in both cell lines. Lee and colleagues suggested that $\mathrm{SN}$-isolated glycoprotein induced caspase-3-dependent apoptosis in HT-29 cells [36], whereas the present results indicate that AE-SN treatment cannot activate cleavage of caspase- 3 in HT-29 cells. These conflicting results provide an important reminder that the biological effects of medicinal herbs may vary according to different preparation and purification methods. Moreover, several studies suggested that the AE-SN-induced apoptosis is due to the presence of steroid alkaloids and phytoglycoproteins in AE-SN [21, 37-39], whereas the chemical compound responsible for AE-SN-induced tumor cell death remained unknown. In order to clarify the exact tumor suppression mechanism, further investigation for identification of effective compounds in AE-SN is therefore required. Nevertheless, the present data suggest that AE-SN may be a potential drug for dealing with colorectal cancer cells, particularly when they are resistant to apoptosis-based chemotherapeutic drugs.

Since AE-SNinduced cytotoxicity in a caspase-3- independent manner, cotreatment of AE-SN with apoptotic activators may further enhance cytotoxicity in tumor cells. AE-SN co-treatment significantly enhanced cytotoxicity in all tested chemotherapy drugs. Although HT-29 is a more AE-SN-resistant cell line, a low dose of AE-SN at $0.5 \mathrm{mg} / \mathrm{mL}$ still demonstrated a synergistic effect as good as a higher dose of $1 \mathrm{mg} / \mathrm{mL}$ with all tested drugs. AE$\mathrm{SN}$-induced LC3 A/B II accumulation was also present in cisplatin/doxorubicin/docetaxel-treated cells, and cleaved caspase-3 was induced by these chemotherapeutic drugs in DLD-1, but not HT-29 cells. Meanwhile, 5-Fu treatment induced cell death independent of activation of caspase-3in both cell lines. Both caspase- 3 dependent/independent cell death induced by chemotherapeutic drugs can be further enhanced by AE-SN treatment. Compared with AE$\mathrm{SN}$ treatment alone, co-treatment with chemotherapeutic drugs decreased the fold induction of LC3 A/B II in both cell lines. For example, cotreatment of $1 \mathrm{mg} / \mathrm{mL}$ AE-SN and $5 \mu \mathrm{M}$ doxorubicin decreased the induction fold from 12.83 and 7.08-fold to 2.09 and 2.05-fold in DLD-1 and HT-29 cells, respectively. Moreover, higher fold induction of LC3 A/B II accumulation was observed in HT-29 compared with that absaved in DLD-1 cells (3.35- versus 4.78-fold) with co-treatment of cisplatin and AE-SN. This suggests that treatment with chemotherapeutic drugs may disrupt AE-SNinduced autophagy in colorectal carcinoma cells regardless of the synergistic cytotoxic effects observed under AE-SN co-treatment, and this disruption may differ by cancer cell types and selected chemotherapeutic drugs. Interestingly, autophagy activated by AE-SN on DLD-1 and HT-29 cells had no protective effect against all tested chemotherapeutic drugs. This finding supported the previous study using autophagic inhibitors, and suggested AE-SN induced autophagy did not play a protective role in HT-29 and DLD1 cells. Further investigation on the relationship of AE$\mathrm{SN}$-induced autophagy and cell death may help clarify the molecular mechanism involved in the drug cross-interaction. Collectively, these results indicate that $\mathrm{AE}-\mathrm{SN}$ is a potential candidate for integration in chemotherapeutic regimens.

Although AE-SN demonstrated an observed tumor suppression efficacy alone and was also capable of enhancing tumor cell death induced by chemotherapeutic drugs the in 
vitro evidence provided here requires further verification in vivo. In order to assess the tumor suppression efficiency in vivo, the optimal administration approach and dosage of AE$\mathrm{SN}$ alone or in combination with individual chemotherapeutic drugs must be further examined with appropriate animal cancer models. Any unexpected adverse effects of the application of AE-SN must be carefully investigated in vivo prior to consideration for further clinical trials. AE-SN dramatically reduced the $\mathrm{IC}_{50}$ doses of all tested chemotherapeutic drugs. Reduced dosage of chemotherapeutic drugs also suggests potentially more tolerance of adverse effects by colorectal cancer patients.

\section{Conclusion}

In this study, AE-SN demonstrated a tumor suppression efficacy against DLD-1 and HT-29 human colorectal carcinoma cells and further enhanced tumor cell death with tested chemotherapeutic drugs in human colorectal carcinoma cells. AE-SN induced tumor cell death in a caspase-3- independent manner on HT-29 and DLD-1 cells with activation of autophagy. Although the full mechanism of AE-SN-induced cell death was still unclear, AE-SN was capable of enhancing cell death activated by cisplatin/doxorubicin/docetaxel/5-Fu (Figure 6). In conclusion, AE-SN is a potential candidate to development of the complementary for colorectal cancer.

\section{Conflict of Interests}

The authors declare that there is no conflict of interests.

\section{Authors' Contribution}

Chen-Jei Tai and Chien-Kai Wang contribute equally to this work.

\section{Acknowledgment}

This work was supported by Chi Mei Medical Center (101CMTMU-12-3).

\section{References}

[1] M. P. Coleman, M. Quaresma, F. Berrino et al., "Cancer survival in five continents: a worldwide population-based study (CONCORD)," The Lancet Oncology, vol. 9, no. 8, pp. 730-756, 2008.

[2] Cancer Registry Annual Report, Department of Health, Executive Yuan, Taiwan, 2009.

[3] S. De Dosso, C. Sessa, and P. Saletti, "Adjuvant therapy for colon cancer: present and perspectives," Cancer Treatment Reviews, vol. 35, no. 2, pp. 160-166, 2009.

[4] S. Kopetz, D. Freitas, A. F. C. Calabrich, and P. M. Hoff, "Adjuvant chemotherapy for stage II colon cancer," Oncology, vol. 22, no. 3, pp. 260-270, 2008.

[5] E. Ernst and B. R. Cassileth, "The prevalence of complementary/ alternative medicine in cancer: a systematic review," Cancer, vol. 83, pp. 777-782, 1998.

[6] R. E. Patterson, M. L. Neuhouser, M. M. Hedderson et al., "Types of alternative medicine used by patients with breast, colon, or prostate cancer: predictors, motives, and costs," Journal of Alternative and Complementary Medicine, vol. 8, no. 4, pp. 477-485, 2002.

[7] M. A. Richardson, T. Sanders, J. L. Palmer, A. Greisinger, and S. E. Singletary, "Complementary/alternative medicine use in a comprehensive cancer center and the implications for oncology," Journal of Clinical Oncology, vol. 18, no. 13, pp. 25052514, 2000.

[8] L. An, J. Tang, X. Liu, and N. Gao, "Review about mechanisms of anti-cancer of Solanum nigrum," Zhongguo Zhongyao Zazhi, vol. 31, no. 15, pp. 1225-1260, 2006.

[9] S. L. McCarthy, R. J. Hinde, K. J. Miller, J. S. Anderson, H. Basch, and M. Krauss, "Theoretical studies of cis-Pt(II)-diammine binding to duplex DNA," Biopolymers, vol. 29, no. 4-5, pp. 823836, 1990.

[10] V. Ganansia-Leymarie, P. Bischoff, J. Bergerat, and V. Holl, "Signal transduction pathways of taxanes-induced apoptosis," Current Medicinal Chemistry, vol. 3, no. 4, pp. 291-306, 2003.

[11] F. Zhang, T. Zhang, Y. Qu et al., "Replication-dependent $\gamma$ $\mathrm{H} 2 \mathrm{AX}$ formation is involved in docetaxel-induced apoptosis in NSCLC A549 cells," Oncology Reports, vol. 24, no. 5, pp. 12971305, 2010.

[12] R. A. Forrest, L. P. Swift, A. Rephaeli et al., "Activation of DNA damage response pathways as a consequence of anthracyclineDNA adduct formation," Biochemical Pharmacology, vol. 83, no. 12, pp. 1602-1612, 2012.

[13] J. Cummings and J. F. Smyth, "DNA topoisomerase I and II as targets for rational design of new anticancer drugs," Annals of Oncology, vol. 4, no. 7, pp. 533-543, 1993.

[14] M. S. Mano and F. Duhoux, "Colon cancer: update on adjuvant therapy," Clinical Colorectal Cancer, vol. 7, no. 3, pp. 178-183, 2008.

[15] A. de Gramont, A. De Gramont, B. Chibaudel, A. K. Larsen, C. Tournigand, and T. Andr, "The evolution of adjuvant therapy in the treatment of early-stage colon cancer," Clinical Colorectal Cancer, vol. 10, no. 4, pp. 218-226, 2011.

[16] L. Lombardi, F. Morelli, S. Cinieri et al., "Adjuvant colon cancer chemotherapy: where we are and where we'll go," Cancer Treatment Reviews, vol. 36, supplement 3, pp. S34-S41, 2010.

[17] D. B. Longley, D. P. Harkin, and P. G. Johnston, "5-Fluorouracil: mechanisms of action and clinical strategies," Nature Reviews Cancer, vol. 3, no. 5, pp. 330-338, 2003.

[18] W. Xu, A. D. Towers, P. Li, and J.-P. Collet, “Traditional Chinese medicine in cancer care: perspectives and experiences of patients and professionals in China," European Journal of Cancer Care, vol. 15, no. 4, pp. 397-403, 2006.

[19] F. Qi, A. Li, Y. Inagaki et al., "Chinese herbal medicines as adjuvant treatment during chemo- or radio-therapy for cancer," Bioscience Trends, vol. 4, no. 6, pp. 297-307, 2010.

[20] M. Youns, J. D. Hoheisel, and T. Efferth, "Traditional Chinese Medicines (TCMs) for molecular targeted therapies of umours," Current Drug Discovery Technologies, vol. 7, no. 1, pp. 37-45, 2010.

[21] K. Hu, H. Kobayashi, A. Dong, Y. Jing, S. Iwasaki, and X. Yao, "Antineoplastic agents III: steroidal glycosides from Solanum nigrum," Planta Medica, vol. 65, no. 1, pp. 35-38, 1999.

[22] H. C. Huang, K. Y. Syu, and J. K. Lin, "Chemical composition of Solanum nigrum linn extract and induction of autophagy by leaf water extract and its major flavonoids in AU565 breast cancer cells," Journal of Agricultural and Food Chemistry, vol. 58, no. 15, pp. 8699-8708, 2010. 
[23] M. Shokrzadeh, M. Azadbakht, N. Ahangar, A. Hashemi, and S. S. Saeedi Saravi, "Cytotoxicity of hydro-alcoholic extracts of Cucurbita pepo and Solanum nigrum on HepG2 and CT26 cancer cell lines," Pharmacognosy Magazine, vol. 6, no. 23, pp. 176-179, 2010.

[24] C. J. Tai, C. K. Wang, Y. J. Chang, and C. S. Lin, "Aqueous extract of Solanum nigrum leaf activates autophagic cell death and enhances docetaxel-induced cytotoxicity in human endometrial carcinoma cells," Evidence-Based Complementary and Alternative Medicine, vol. 2012, Article ID 859185, 10 pages, 2012.

[25] H. M. Lin, H. C. Tseng, C. J. Wang et al., "Induction of autophagy and apoptosis by the extract of Solanum nigrum Linn in HepG2 cells," Journal of Agricultural and Food Chemistry, vol. 55, no. 9, pp. 3620-3628, 2007.

[26] I. Tanida, T. Ueno, and E. Kominami, "LC3 and autophagy," Methods in Molecular Biology, vol. 445, pp. 77-88, 2008.

[27] T. C. Chou, "Theoretical basis, experimental design, and computerized simulation of synergism and antagonism in drug combination studies," Pharmacological Reviews, vol. 58, no. 3, pp. 621-681, 2006.

[28] A. Petiot, E. Ogier-Denis, E. F. C. Blommaart, A. J. Meijer, and P. Codogno, "Distinct classes of phosphatidylinositol 3'kinases are involved in signaling pathways that control macroautophagy in HT-29 cells," Journal of Biological Chemistry, vol. 275, no. 16, pp. 992-998, 2000.

[29] A. Yamamoto, Y. Tagawa, T. Yoshimori, Y. Moriyama, R. Masaki, and Y. Tashiro, "Bafilomycin Al prevents maturation of autophagic vacuoles by inhibiting fusion between autophagosomes and lysosomes in rat hepatoma cell line, H-4-II-E cells," Cell Structure and Function, vol. 23, no. 1, pp. 33-42, 1998.

[30] I. Tanida, N. Minematsu-Ikeguchi, T. Ueno, and E. Kominami, "Lysosomal turnover, but not a cellular level, of endogenous LC3 is a marker for autophagy," Autophagy, vol. 1, no. 2, pp. 84-91, 2005.

[31] E. White, "Deconvoluting the context-dependent role for autophagy in cancer," Nature Reviews Cancer, vol. 12, pp. 401410, 2012.

[32] A. M. Choi, S. W. Ryter, and B. Levine, "Autophagy in human health and disease," The New England Journal of Medicine, vol. 368, pp. 1845-1846, 2013.

[33] J. Li, N. Hou, A. Faried, S. Tsutsumi, and H. Kuwano, "Inhibition of autophagy augments 5-fluorouracil chemotherapy in human colon cancer in vitro and in vivo model," European Journal of Cancer, vol. 46, no. 10, pp. 1900-1909, 2010.

[34] D. Chendil, R. Oakes, R. A. Alcock et al., "Low dose fractionated radiation enhances the radiosensitization effect of paclitaxel in colorectal tumor cells with mutant p53," Cancer, vol. 89, pp. 1893-1900, 2000.

[35] D. Rajesh, K. Schell, and A. K. Verma, "Ras mutation, irrespective of cell type and p53 status, determines a cell's destiny to undergo apoptosis by okadaic acid, an inhibitor of protein phosphatase 1 and 2A," Molecular Pharmacology, vol. 56, no. 3, pp. 515-525, 1999.

[36] S. J. Lee, J. H. Ko, and K. T. Lim, "Glycine- and proline-rich glycoprotein isolated from Solanum nigrum Linne activates caspase-3 through cytochrome c in HT-29 cells.," Oncology reports, vol. 14, no. 3, pp. 789-796, 2005.

[37] Y. B. Ji, S. Y. Gao, C. F. Ji, and X. Zou, "Induction of apoptosis in HepG2 cells by solanine and Bcl-2 protein," Journal of Ethnopharmacology, vol. 115, no. 2, pp. 194-202, 2008.

[38] P. S. Oh and K. T. Lim, "HeLa cells treated with phytoglycoprotein $(150 \mathrm{kDa})$ were killed by activation of caspase 3 via inhibitory activities of NF- $\kappa$ B and AP-1," Journal of Biomedical Science, vol. 14, no. 2, pp. 223-232, 2007.

[39] Y.-O. Son, J. Kim, J.-C. Lim, Y. Chung, G.-H. Chung, and J.-C. Lee, "Ripe fruits of Solanum nigrum L. inhibits cell growth and induces apoptosis in MCF-7 cells," Food and Chemical Toxicology, vol. 41, no. 10, pp. 1421-1428, 2003. 


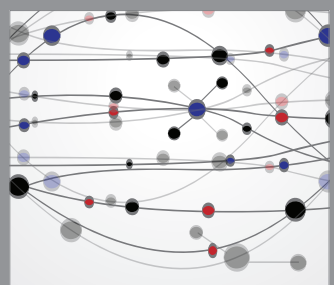

The Scientific World Journal
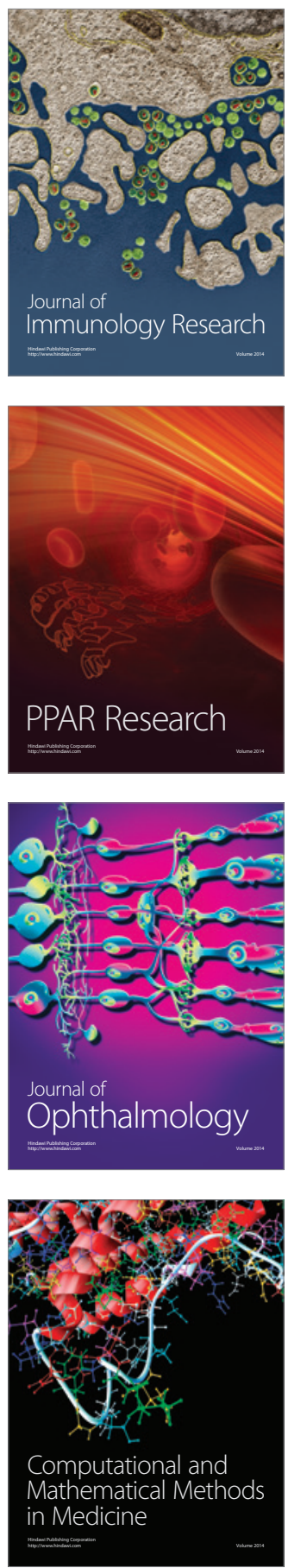

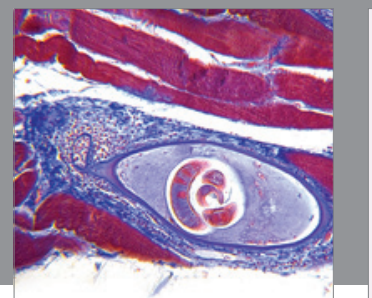

Gastroenterology

Research and Practice
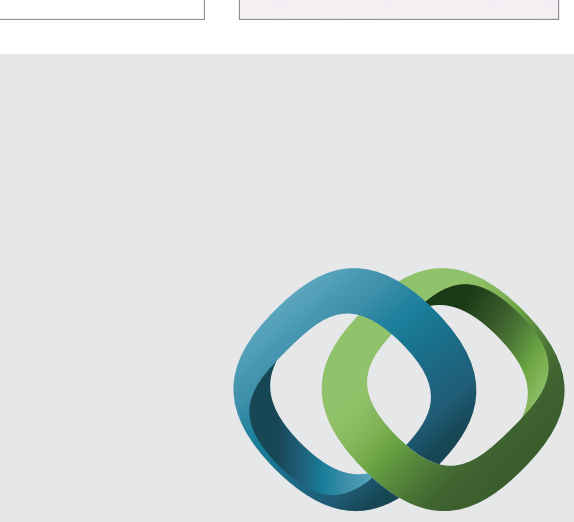

\section{Hindawi}

Submit your manuscripts at

http://www.hindawi.com
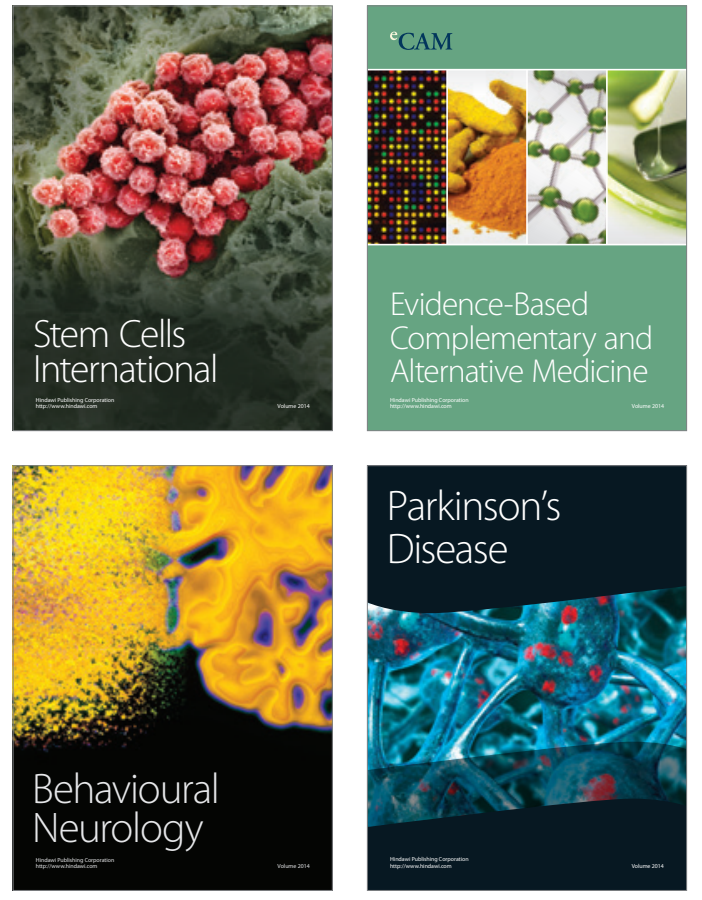
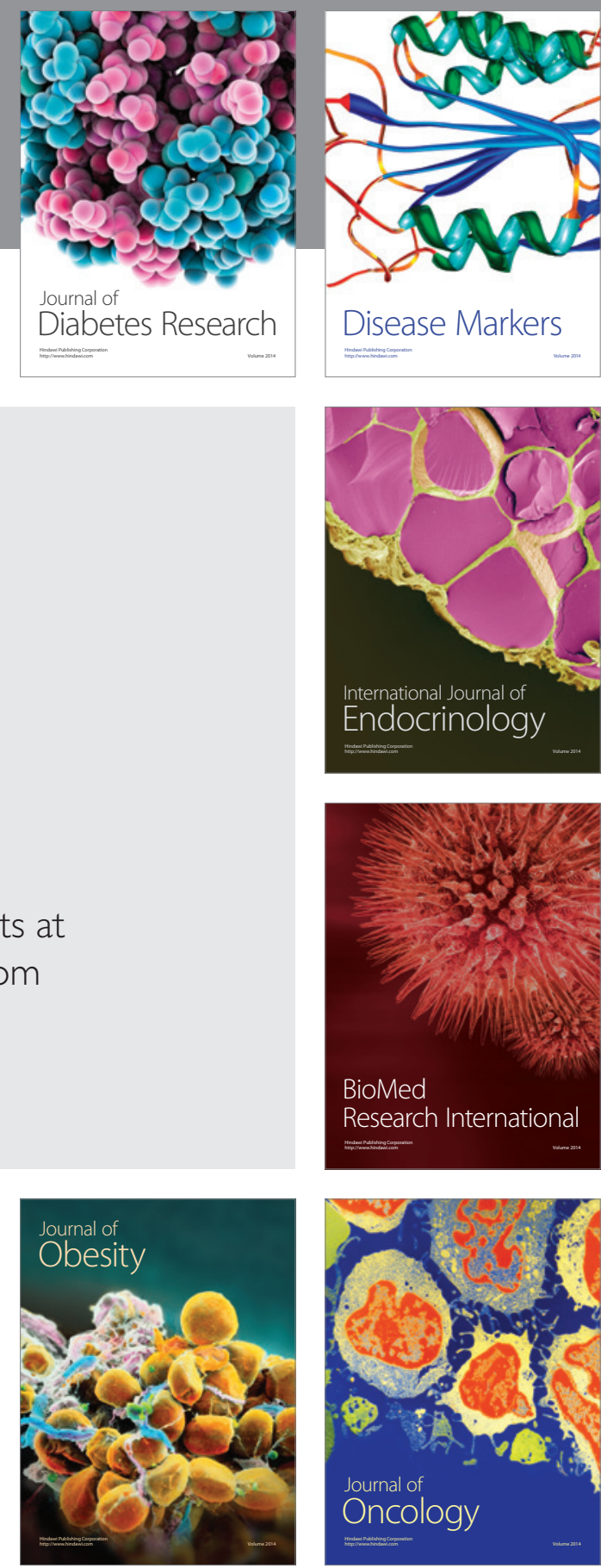

Disease Markers
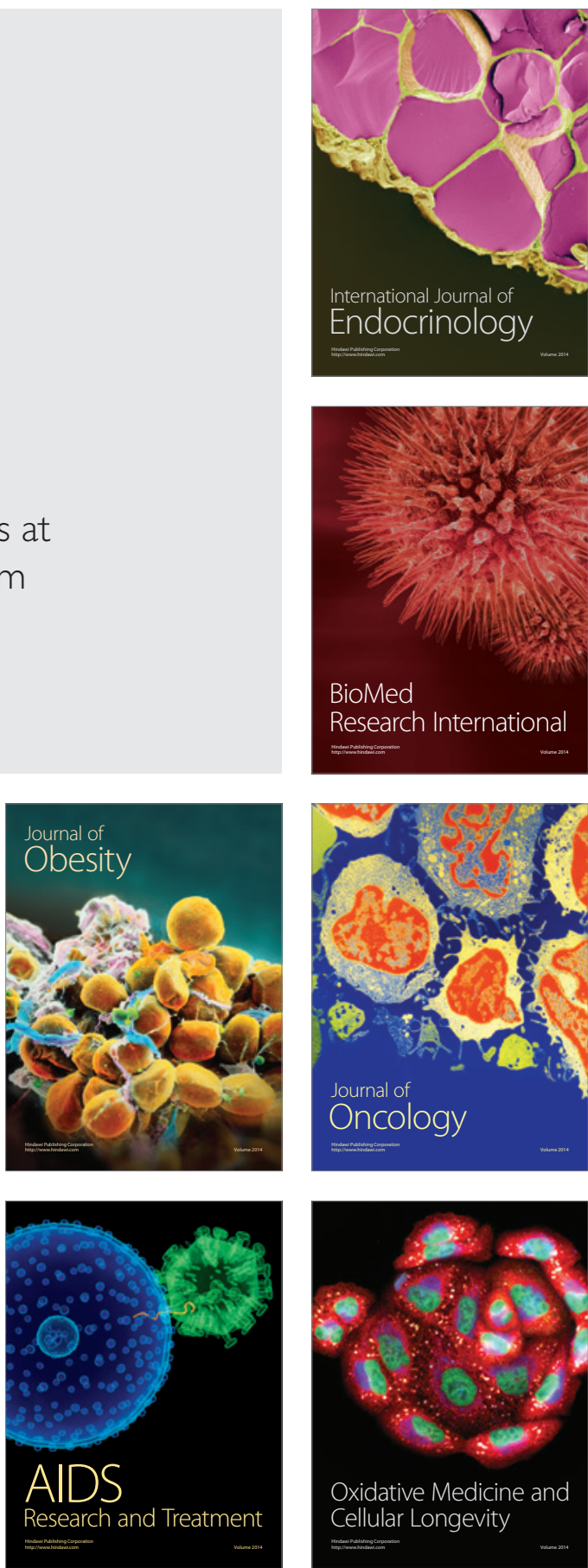